\title{
ESTUDO RETROSPECTIVO DO LEVANTAMENTO DE PROBLEMAS DE ENFERMAGEM E SUA CORRELAÇÃO COM A PRESCRIÇÃO DE ENFERMAGEM *
}

\author{
Suely Sueko Viski Zanei". \\ Maria Ester Dias de Oliveira"*." \\ Dayse Zamudio Lopes Ernesto".." \\ Orientadoras: \\ Sandra Honorato da Silva \\ Sofia Maria Taffil Bello Valente
}

ZANEI, S.S.V.; OLIVEIRA, M.E.D. de; ERNESTO, D.Z.L. Estudo retrospectivo do levantamento de problemas de enfermagem e sua correlação com a prescrição de enfermagem. Rev. Esc. Enf. USP, São Paulo, 22 (n. especial): 119-147, jun. 1988.

Este estudo foi realizado no Instituto do Coração do Hospital das Clínicas da Faculdade de Medicina da Universidade de São Paulo, onde a assistência de enfermagem tem como objetivo primordial a individualização e a qualificação da assistência prestada. Durante estágios práticos, realizados nas unidades de internação dessa instituição, observou-se uma certa inadequação entre o modelo teórico e sua operacionalização prática. $\mathrm{Na}$ tentativa de demonstrar a real situação da assistência de enfermagem, este estudo enfocou a correlação entre as etapas de levantamento de problemas com a prescrição de enfermagem, categorizando os problemas de enfermagem em psicobiológicos, psicossociais e psicoespirituais. Por meio dos resultados obtidos verificou-se a necessidade de reavaliação da metodologia utilizada. Elaborou-se, ainda, considerações pertinentes ao tema.

UNITERMOS: Assistência de enfermagem. Prescrição de enfermagem. Planejamento da assistência ao paciente.

\section{INTRODUÇĀO}

\subsection{DEFINIÇÃO DO PROBLEMA}

A vivência profissional das autoras, bem como as observações realizadas durante estágios em unidades de internação do Instituto do Coração do Hospital das Clínicas da Faculdade de Medicina da Universidade de

\footnotetext{
- Trabalho realizado durante II Curso de Especlalização em enfermagem em cardiologla - Modalldade de Residência - EEUSP-INCOR-1986.

- Enfermeira do Curso de Especlalização em Enfermagem em Cardiologia na Modalldade de Residência EEUSP-INCOR e Enfermeira do Hospital Ipiranga - INAMPS - SP.

*.* Enfermeira do Curso de Especialização em Enfermagem em Cardiologia na Modalldade de Residéncla EEUSP-INCOR.
} 
São Paulo (InCor-HCFMUSP), onde a assistência de enfermagem está baseada numa metodologia específica, tem mostrado uma certa inadequação entre o modelo teórico adotado e sua operacionalização prática.

Uma certa dificuldade parece estar ocorrendo entre alguns profissionais no sentido de propor ações que atendam toda a gama de problemas de enfermagem apresentados pelo paciente durante sua hospitalização, visando uma assistência global ao ser humano no atendimento de suas necessidades humanas básicas. Constatou-se ainda, que durante o período de internação, ocorreram com freqüência, mudanças no estado geral do paciente em seus aspectos físicos e psicossociais, gerando assim novos problemas de enfermagem. Muitas vezes tais problemas são abordados nas prescrições de enfermagem, sem no entanto passarem a compor 0 elenco de problemas, fase preconizada na metodologia adotada, para que se tenha uma visão geral da problemática de enfermagem apresentada pelo paciente durante sua permanência na instituição.

Outro fator de grande relevância observado diz respeito as ações de enfermagem propostas nas prescrições de enfermagem. Sabe-se que embora o paciente seja filosoficamente concebido como um ser global (biopsicossociospiritual), notou-se que a maioria das ações de enfermagem prescritas pelo enfermeiro está relacionada ao atendimento das necessidades da área psicobiológica, enquanto que as áreas psicossocioespirituais apresentam propostas de.ações numa proporção bem menor.

A busca de conhecimento para adequar modelos teóricos à prática de enfermagem diária e os fatos expostos motivaram o presente trabalho.

\subsection{REVISÃO BIBLIOGRÁFICA}

Tem-se observado uma preocupação cada vez maior por parte dos profissionais de enfermagem em se adotar um modelo assistencial com bases científicas para a resolução dos problemas apresentados pelo paciente.

Assim, em nosso meio constata-se um grande enfoque na literatura de enfermagem direcionada a uma metodologia própria, objetivando principalmente a melhoria da qualidade de assistência prestada.

Segundo PAIM ${ }^{20}$, “a enfermagem se esforça nos dias presentes, no sentido de abandonar o modo empírico de atuação, para passar a fazê-lo cientificamente, isto é, mediante o emprego de uma metodologia científica".

HORTA ${ }^{11}$ e PAIM ${ }^{20}$, entre outros, propuseram uma metodologia de assistência de enfermagem, denominada de Processo de Enfermagem. Para HORTA vem a ser "a dinâmica das ações sistematizadas visando a assistência ao ser humano. Caracteriza-se pelo inter-relacionamento e dinamismo de suas fases". PAIM ${ }^{20}$ considera o Processo de Enfermagem como "um conjunto de procedimentos a que é submetido o homem (família, comunidade e sociedade) dependente da assistência de enfermagem, visando torná-lo independente em relação a este tipo de serviço". 
DANIEL ${ }^{8}$ denomina Plano Terapêutico de Enfermagem a "elaboração de um planejamento sistemático de assistência de enfermagem, plano este que compõe todo o processo de ação e decisão destinadas a programar os cuidados de enfermagem".

FERNANDES ${ }^{9}$ afirma que "o Processo de Enfermagem não é uma fórmula mágica, mas é a sistematização das ações do enfermeiro, com base no método de resolução de problemas, impelindo-o a assumir a responsabilidade da assistência ao paciente no que tange a enfermagem".

ANGERAMI ${ }^{1}$ ao se referir a teoria das necessidades básicas de HORTA, que fundamenta o Processo de Enfermagem, enfatiza, "para que esta teoria se torne prática é necessário qoe nossos profissionais sejam exímios observadores a fim de que possam, através desse método, identificar os problemas de enfermagem, estabelecer um diagnóstico, traçar um plano de ação e avaliar se utrabalho". Conclui que, dessa forma, estaria sendo utilizada a metodologia científica na assistência de enfermagem.

KRON ${ }^{12}$ afirma que "o Processo de Enfermagem consiste na avaliação do paciente e de suas necessidades, no planejamento de como satisfazer essas necessidades, na execução dos planos e na avaliação dos resultados da intervenção planejada". Completa enfatizando que "é essencialmente um processo de resolver problemas, com ênfase na tomada de decisões a respeito da assistência de enfermagem de que o paciente necessita".

A implantação de uma metodologia de assistência de enfermagem parece trazer inúmeros benefícios tanto para o paciente como para a equipe de enfermagem. Desta forma, vários autores têm confirmado as vantagens da aplicação de um método de assistência ${ }^{3,8}$, 10, 11, 17, 18, 21 e 22 .

ROLIM ${ }^{21}$ cíca as seguintes "vantagens para o paciente:

— individualização do paciente;

- atendimento de suas necessidades em função dos problemas identificados;

- segurança d̛o paciente em razão dos cuidados recebidos.

Para a equipe de enfermagem:

- conhecimento mais profundo do paciente;

- identificação de seus problemas em função de suas necessidades básicas;

- planejamento do trabalho, de forma a solucionar os problemas encontrados;

- facilidade na avaliação da evolução do paciente;

- segurança da equipe pela utilização do método científico para a solução dos problemas do paciente".

Com a utilização do Processo de Enfermagem, o paciente é o principal beneficiado. Consolidando tal afirmativa, FERNANDES ${ }^{9}$ cita que "o Processo de Enfermagem eleva o nível de assistência prestada, porque procura atender pelo menos, teoricamente, as necessidades afetadas do paciente 
e que estes sentem os efeitos dessa modalidade de assistência, quer pela maior satisfação quanto aos cuidados recebidos, quer por uma recuperação mais rápida".

Quanto a responsabilidade do enfermeiro em relação ao Processo de Enfermagem, KRON ${ }^{12}$ afirma que o enfermeiro "deve planejar a assistência de seu paciente e colocar seu paciente e colocar seu plano em ação delegando atividades, supervisionando e ensinando aqueles que prestam a assistência. Ele pode delegar muitos procedimentos e tarefas ao pessoal auxiliar: todavia não pode delegar a sua responsabilidade profissional de planejar, supervisionar e avaliar a assistência que a equipe de enfermagem dá ao paciente".

Um outro aspecto da responsabilidade do enfermeiro enfocado por PAIM ${ }^{18}$ é que este profissional deve garantir a qualidade do cuidado de enfermagem que é prestada às pessoas hospitalizadas.

O Processo de Enfermagem não só beneficia o cliente-paciente e a equipe de enfermagem, como também valoriza o profissional frente à equipe de saúde, ao paciente, família e comunidade. Além disso, promove o seu desenvolvimento científico e como conseqüência possibilita a meIhora progressiva da qualidade de assistência prestada.

GUTIERREZ ${ }^{10}$ afirma que "a aplicação do Processo de Enfermagem é uma condição essencial para o progresso e autonomia da profissão".

PAIM ${ }^{18}$ cita que, "à medida em que o enfoque central das atividades dos enfermeiros passe a ser o fortalecimento de sua responsabilidade com a prescrição no plano de cuidados cresce uma convicção de que, somente desse modo, estará fortalecida a autonomia desses profissionais em campo de prática..."

Para que o enfermeiro aplique o Processo de Enfermagem na prática diária há necessidade de adquirir conhecimento e desenvolver habilidades específicas. Nessa linha de raciocínio, CLARK ${ }^{6}$ afirma que somente o enfermeiro é competente para prescrever os cuidados de enfermagem, porque só ele possui o conhecimento e as habilidades exigidas.

MOUGHTON ${ }^{16}$ aprofunda-se nessa temática e ressalta que o plano de cuidados, entendido como Processo de Enfermagem, pode ser utilizado, também, como um instrumento para avaliar o nível de competência da enfermagem. Para ela, competência envolve mais do que conhecimento e habilidade. O comportamento competente é a presteza para se utilizar do conhecimento no momento apropriado, com uma atitude adequada, habilidade para perceber o que é necessário e o compromisso para dar os passos corretos para realizar determinada tarefa. Conclui, dizendo que a qualidade do cuidado que fornecemos ao público é uma verdadeira reflexão de nosso conceito de enfermagem.

Com o intuito de conscientizar o futuro enfermeiro sobre a importância de uma metodologia para a qualificação da assistência, o Processo de Enfermagem de HORTA, precursor de uma metodologia assistencial no 
Brasil, parece ser o mais adotado na maioria das escolas de enfermagem ${ }^{3}$. Algumas instituições hospitalares no município de São Paulo, preocupadas quanto a qualidade de assistência prestada, implantaram o Processo de Enfermagem adaptando-o às suas necessidades e recursos.

HORTA 11 apresenta o modelo de Processo de Enfermagem dividindo-o em seis fases. O histórico de enfermagem, início do processo, "é um roteiro sistematizado para o levantamento de dados do paciente, família ou comunidade a fim de tornar possivel a identificação dos seus problemas". Para a autora, problemas de enfermagem "são situações ou condições de desequilíbrio das necessidades do indivíduo, família e comunidade, e que exigem do enfermeiro sua assistência profissional". Ela adotou para o seu trabalho a denominação de MOHANA ${ }^{15}$ que classifica as necessida. des básicas em psicobiológicas, psicossociais e psicoespirituais.

A segunda fase é o diagnóstico de enfermagem, definido como "identificação das necessidades do ser humano que precisa de atendimento e a determinação pelo enfermeiro do grau de dependência deste atendimento em natureza e em extensão".

O plano assistencial, terceira fase, é a "determinação global da assistência de enfermagem que o ser humano deve receber diante do diagnóstico estabelecido".

A seguir, o plano de cuidados ou prescrição de enfermagem, que corresponde à quarta fase, é “a implementação do plano assistencial pelo roteiro diário que coordena a ação da aquipe de enfermagem na execução dos cuidados adequados no atendimento das necessidades básicas e específicas do ser humano".

A evolução da enfermagem, quinta fase, "é o relato diário das mudanças sucessivas que ocorrem no ser humano: enquanto estiver sob assistência profissional. É a avaliação global do plano de cuidados".

Finalizando, o prognóstico de enfermagem é a "estimativa da capacidade do ser humano em atender as necessidades básicas alteradas após a implantação do plano assistencial. A autora acrescenta que o prognóstico é também "um meio de avaliação do processo em si, mede todas as fases e chega a uma conclusão".

Para a operacionalização do processo de enfermagem, há necessidade de se adotar um instrumento que possibilite registros adequados de toda assistência prestada. Este instrumento deve facilitar a continuidade de tratamento, direcionar as ações da equipe de enfermagem, servir de veículo de educação continuada e comunicação entre os elementos da equipe de saúde. Além disso, deve fornecer subsídios para avaliação da qualidade e quantidade da assistência de enfermagem oferecida.

Segundo KURCGANT ${ }^{14}$, "o plano de cuidados pode ser visto como um instrumento administrativo sob vários aspectos: como agente de comunicação, elemento de educação continuada, catalizador de atividades, indicador de controle e avaliação. Essa definição pode ser aplicada ao Processo 
de Enfermagem, uma vez que para o enfermeiro chegar à fase do plano de cuidados, ele terá, que previamente, se utilizar de outros recursos, mesmo que não registrados, mas elaborados mentalmente no sentido de embasar as ações propostas.

O desenvolvimento de uma metodologia, em qualquer área de atividade humana, exige avaliações periódicas, para que hajam mudanças de acordo com as respectivas necessidades.

Conforme afirma KRON 12 "a etapa final do processo de enfermagem é a avaliação da adequação das ações de enfermagem e seus resultados. O plano de assistência de enfermagem deve ser revisado para determinar sua relevância e eficácia em ajudar o paciente e sua família nos seus problemas com saúde/bem estar".

$\operatorname{COSTA}^{7}$ relata também, que o "processo de avaliação deve ser entendido como um mecanismo regulador e raelimentador ao substrato profissional, no todo ou em parte, no domínio das funções técnicas e administrativas".

KURCGANT ${ }^{13}$ cita ainda que "a atuação da enfermagem deve, fundamentalmente, ser avaliada pelos resultados obtidos na avaliação das atividades desenvolvidas no cuidado dos pacientes".

BERGMAN ${ }^{4}$ enfatiza quatro beneficiados principais através da avaliação: os destinatários (pacientes e clientes), os enfermeiros, as estruturas de saúde e a profissão. Para ela, o objetivo principal são os destinatários, para fornecer-lhes um tipo de serviço que seja seguro, o mais eficaz e o mais satisfatório possível em uma dada situação. Para os enfermeiros, a avaliação é uma ocasião para o crescimento pessoal e profissional, constituindo-se de um estímulo para melhora nesses dois aspectos. Quanto às estruturas de saúde a avaliação é um meio para verificar a obtenção de alguns propósItos, obter uma base para a continuidade da programação estabelecida, permitir a contenção de custos e prover dados para proteção legal. Finalmente, para a profissão, os benefícios são o desenvolvimento de padrões e protocolos, e a obtenção de novos conhecimentos.

KURCGANT ${ }^{13}$ afirma que "os cuidados de enfermagem podem ser avaliados através dos registros, logo, a avaliação dos registros, conseqüentemente, reflete a qualidade de enfermagem."

Um dos meios utilizados para a avaliação dos registros é a auditoria que, segundo Santos citado por SOUZA ${ }^{22}$, consiste na "verificação da regularidade ou irregularidade das operações realizadas dentro de um período, a fim de se poder certificar sobre a veracidade e exatidão do resultado relativo ao mesmo período".

Dunn e Morgan, citados por ARAUJO ${ }^{2}$, definem auditoria como "um instrumento de administração utilizado na avaliação da qualidade do cuidado; é a comparação entre a assistência prestada e os padrões de assistência considerados como aceitáveis". 
Para CERQUEIRA 5 a auditoria de enfermagem é "o processo pelo qual as atividades de enfermagem são examinadas, mensuradas e avaliadas, em confronto com padrões pré-estabelecidos, por meio de revisões de anotações de enfermagem que constam do Prontuário Médico". Complementando, ARAUJO ${ }^{2}$ acrescenta que "a auditoria colabora com o desenvolvimento da profissão como ciência, de maneira constante, consistente e progressiva".

Considerando-se o problema já definido na primeira parte desta introdução, e a fundamentação fornecida pela literatura consultada, as autoras, na tentativa de constatar a real situação da metodologia de assistência de enfermagem na instituição, utilizaram-se de um método para a avaliação da qualidade de assistência.

Neste trabalho, em particular, foi utilizada a auditoria retrospectiva, ou seja, aquela realizada após a alta do paciente, utilizando-se o prontuário como fonte de informação sobre a assistência prestada ao paciente e documentada.

\subsection{OBJETIVOS:}

Os objetivos do presente trabalho são:

1 - Inventariar e categorizar os problemas de enfermagem registrados no prontuário do paciente nas fases da Sistemática de Assistência de Enfermagem.

2 - Verificar se os problemas de enfermagem identificados nas fases de levantamento de problemas da Sistemática de Assistência de Enfermagem estão relacionados no elenco de problemas.

3 - Investigar se todos os problemas relacionados no elenco de problemas foram abordados na prescrição de enfermagem.

4 - Verificar a que categoria pertencem os problemas de enfermagem abordados na prescrição de enfermagem.

5 - Verificar, de acordo com sua categoria, se os problemas inventariados foram abordados na prescrição de enfermagem.

\subsection{DEFINIÇÃO DE TERMOS}

Para este estudo foram adotadas as seguintes definições:

PROBLEMA DE ENFERMAGEM: "são situações decorrentes dos desequilíbrios das necessidades básicas do indivíduo, família e comunidade, e que exigem do enfermeiro sua assistência profissional ${ }^{n}$ (HORTA) ${ }^{11}$.

PROBLEMA INVENTARIADO: Todo o problema de enfermagem detectado nas diversas fases da $S A E$, e transcrito pelos pesquisadores na folha de coleta de dados.

PROBLEMA ELENCADO: é todo o problema transcrito pelo enfermeiro na folha de elenco de problemas, para o qual é proposta uma ação de 
enfermagem, de acordo com a classificação: fazer, ajudar orientar, supervisionar e encaminhar (FAOSE) utilizada por HORTA.

PROBLEMA PSICOBIOLÓGICO: quando o problema de enfermagem está relacionado à necessidade biológica afetada.

PROBLEMA PSICOSSOCIAL: quando o problema de enfermagem está relacionado à necessidade social afetada.

PROBLEMA PSICOESPIRITUAL: quando o problema de enfermagem está relacionado à necessidade espiritual afetada.

PROBLEMA PSICOBIOLÓGICO E PSICOSSOCIAL: quando o problema de enfermagem está relacionado a necessidade biológica e social concomitantemente.

PROBLEMA PSICOBIOLÓGICO, PSICOSSOCIAL E PSICOESPIRITUAL: quando o problema de enfermagem está relacionado a necessidade biológica, social e espiritual concomitantemente.

PROBLEMA ABORDADO: é todo o problema para o qual o enfermeiro prescreve uma ou mais ações de enfermagem para o paciente no decorrer de sua hospitalização.

EVOLUÇÃO DE ENTRADA: é a anotação feita pelo enfermeiro ou na sua ausência pelo técnico ou auxiliar de enfermagem sobre as condições gerais do paciente no momento da admissão.

EVOLUÇÃO DIARIA DE ENFERMAGEM: é o relato diário e progressivo das respostas ou reações do paciente, submetido às ações de enfermagem e dos demais profissionais envolvidos em seu trabalho, sendo uma atividade executada exclusivamente pelo enfermeiro.

\subsection{CARACTERIZAÇÃO DA SISTEMATICA DE ASSISTENCIA DE ENFERMAGEM NO INSTITUTO DO CORAÇÃO DO HOSPITAL DAS CLÍNICAS DA FACULDADE MEDICINA DA UNIVERSIDADE DE SÃO PAULO}

A metodologia de assistência de enfermagem adotada no InCorHCFMUSP, desde 1982, denomina-se Sistemática de Assistência de Enfermagem (SAE).

Tendo em vista que o objetivo da instituição é a aplicação de uma assistência individualizada, implantou-se o modelo proposto por HORTA ${ }^{11}$ que foi adaptado na tentativa de facilitar a sua operacionalização.

A SAE está centrada em cinco fases: histórico de enfermagem, elenco de problemas, prescrição de enfermagem, evolução e anotação de enfermagem, sendo que as quatro primeiras fases são realizadas exclusivamente pelo enfermeiro e portanto objeto deste estudo.

O histórico de enfermagem (Anexo I) consta dos seguintes itens principais: dados de identificação, exame físico e entrevista. 
Após a realização do histórico de enfermagem, os problemas de enfermagem são detectados, analisados e transcritos para a folha de elenco de problemas (Anexo II). Essa folha permanece no mesmo Kardex, junto com a folt:a de prescrição de enfermagem, visando facilitar a sua consulta.

Para cada problema constatado deve existir uma ação de enfermagem correspondente, segundo as ações propostas por HORTA ou seja: fazer, ajudar, orientar, supervisionar e encaminhar, sendo registrado ao lado a data de início e término de cada ação.

A prescrição de enfermagem (Anexo III) é feita em um impresso próprio. Nessa folha há espaços reservados para o horário em que devem ser executadas as ações, para as anotações da equipe de enfermagem e para a evolução de enfermagem. Para a elaboração da prescrição de enfermgem os enfermeiros utilizam a prescrição e evolução de enfermagem do dia anterior, as informações obtidas através da passagem de plantão, a folha de controle de sinais vitais e elenco de problemas, a prescrição e evolução médica e finalmente deve se utilizar de dados obtidos através da evolução diária do paciente por meio do exame físico e entrevista.

\section{METODOLOGIA}

\subsection{LOCAL DE ESTUDO}

Este estudo foi realizado no Instituto do Coração do Hospital das Clínicas da Faculdade de Medicina da Universidade de São Paulo (InCorFMUSP).

Do hospital, foi selecionada uma unidade do $7 .^{\circ}$ andar ala leste e oeste, em função da homogeneidade do diagnóstico médico dos pacientes e, também, devido ao fato das unidades não terem sofrido alterações na sua planta física, bem como na equipe de enfermagem durante o período de realização deste trabalho, fatores esses que poderiam interferir nos resultados do estudo.

\subsection{POPULAÇÃO}

A população foi constituída de pacientes egressos, de ambos os sexos, com diagnóstico de doença arterial coronariana, em tratamento clínico ou cirúrgico, internados nas alas leste e oeste do $7 .^{\circ}$ andar, e que receberam alta hospitalar nos meses de setembro, outubro e novembro de 1986.

Para tratar-se de análise retrospectiva da assistência de enfermagem prestada durante o período de hospitalização, foram utilizados no estudo os prontuários destes pacientes.

O critério da média de permanência foi adotado tendo por base o fato de se pretender fazer uma análise da assistência de enfermagem prestada ao paciente durante todo o paríodo de sua internação. Para este critério considerou-se a média de permanência de treze dias conforme encontrado nessa unidade no período determinado pelo estudo. A via de entrada do paciente ao hospital foi outro critério adotado em função de se pretender 
trabalhar só com o paciente que tivesse sido admitido, via ambulatório, fato este que levaria o histórico de enfermagem ser elaborado pela enfermeira da unidade de internação, o que possibilitaria a consecução do estudo.

Foram excluídos da população, com o objetivo de não alterar os resultados desse trabalho, os pacientes cujos prontuários não estivessem com os impressos de enfermagem preenchidos, pacientes com média de permanência inferior a 24 horas e superior a 13 dias, pacientes que evoluíram para óbito ou cuja via de entrada não tenha sido a via ambulatorial.

De um total de 413 pacientes internados durante o período estabelecido para o estudo, e aplicando-se os critérios citados, passaram a constituir a amostra deste trabalho um total de 34 pacientes.

\subsection{INSTRUMENTO DE COLETA DE DADOS}

Para a caleta de dados dos prontuários a serem analisados, foi elaborado um instrumento (Anexo IV), onde foram registrados os dados de identificação do paciente e dados específicos para análise posterior.

Este instrumento foi composto de três colunas onde foram transcritos: na primeira coluna, os problemas inventariados no histórico de enfermagem, a evolução de entrada e a evolução diária; na segunda coluna, os problemas relacionados pelo enfermeiro na folha de elenco de problemas e na última coluna, as prescrições de enfermagem. Posteriormente, as ações prescritas foram analisadas para se relacionar a ação proposta ao problema que a desencadeou.

Para se verificar a necessidade de adequação desse instrumento, foi realizado um pré-teste com prontuário de um paciente selecionado de acordo com os critérios estabelecidos.

A aplicação desse instrumento, nessa fase, foi realizado por cinco enfermeiras, dentre elas as autoras desse trabalho $e$ as orientadoras do mesmo. Após a realização do pré-teste verificou-se que o instrumento não necessitaria sofrer adaptação, sendo o mesmo empregado para a coleta de dados dos demais prontuários.

\subsection{DESCRIÇÃO DO METODO}

Para facilitar a operacionalização das coletas dos dados foram determinados quatro passos, a saber:

Primeiro Passo: através da leitura do histórico de enfermagem, evolução de entrada e das evoluções diárias foram transcritos para a folha do instrumento de coleta de dados, os problemas de enfermagem, de acordo com o conceito adotado pela instituição. Estes problemas de enfermagem foram denominados, nesta etapa do trabalho, como problemas inventariados (primeira coluna do Anexo IV).

Segundo Passo: os problemas registrados pelo enfermeiro, na folha de elenco de problemas, foram transcritos para o instrumento de coleta de dados. (segunda coluna). 
Terceiro Passo: as prescrições de enfermagem diárias, realizadas durante o período de internação do paciente, foram transcritos para o instrumento de coleta de dados, com a finalidade de se levantar os problemas abordados por meio das ações de enfermagem propostas. (terceira coluna).

Quarto Passo: os problemas inventariados, elencados e abordados na prescrição de enfermagem, foram categorizados em problemas psicobiológicos, psicossociais e psicoespirituais, de acordo com a classificação das necessidades Humanas-Básicas de MOHANA ${ }^{15}$.

Considerando o interrelacionamento da manifestação e satisfação das necessidades básicas do indivíduo, os problemas decorrentes das mesmas foram classificados como problemas que afetam dois ou três níveis de necessidades concomitantemente. Nesse trabalho, tabagista ativo, higiene oral insatisfatória, ingesta hídrica diminuída, vida sedentária obstipação intestinal, uso de tranqüilizantes, doenças crônicas, uso de medicamentos, obesidade e alterações do estado emocional, foram classificados em psicossocial e psicobiológicos devido ao seu interrelacionamento.

Os problemas classficados em psicobiológico, psicossocial e psicoespiritual foram: cateterismo cardíaco, cirurgia, angioplastia e outros exames invasivos.

Os problemas: etilismo social, prática de esportes, extabagista e utilização de sistema Holter, foram classificados exclusivamente como psicossociais, por efetarem prioritariamente a necessidade de aprendizagem, voltada à educação à saúde.

\section{APRESENTAÇÃO DOS RESULTADOS E COMENTARIOS}

Os resultados obtidos na aplicação do instrumento de análise de assistência de enfermagem foram lançados em tabelas e gráficos e apresentados de acordo com os objetivos propostos.

TABELA 1

Categorização dos problemas inventariados nas etapas de identificação de problemas de SAE. InCor, São Paulo, 1986.

\begin{tabular}{|c|c|c|c|c|c|c|c|c|c|c|}
\hline $\begin{array}{l}\text { Etapas da SAE } \\
\text { Categorias }\end{array}$ & $\begin{array}{l}\text { Ent } \\
\text { N. } \\
\end{array}$ & $\begin{array}{l}\text { v. } \\
\%\end{array}$ & $\begin{array}{l}\text { Ex. F } \\
\text { N. }\end{array}$ & $\begin{array}{c}\text { ico } \\
\%\end{array}$ & N. ${ }^{\circ}$ & $\begin{array}{r}\text { ntr. } \\
\%\end{array}$ & $\begin{array}{l}\text { Ev. D } \\
\text { N.: }\end{array}$ & $\begin{array}{c}\text { iária } \\
\%\end{array}$ & N. ${ }^{\circ}$ & $\begin{array}{l}\text { TAL } \\
\%\end{array}$ \\
\hline - Psicobiológica & 24 & 6,3 & 199 & 51,8 & 11 & 2,9 & 150 & 39,0 & 384 & 100,0 \\
\hline & 28 & 84,8 & - & - & - & - & 5 & 15,2 & 33 & 100,0 \\
\hline $\begin{array}{l}\text { e Psi } \\
\text { - Psicc } \\
\text { Psicc }\end{array}$ & 92 & 65,2 & 19 & 13,5 & 9 & 6,4 & 21 & 14,9 & 141 & 100, \\
\hline & 1 & 6,7 & 一 & - & 3 & 20,0 & 11 & 73,3 & 15 & 100,0 \\
\hline piritual & - & - & - & - & - & - & - & - & - & - \\
\hline & 145 & 25,3 & 218 & 38,1 & 23 & 4,0 & 187 & 32,6 & 573 & 100,0 \\
\hline
\end{tabular}


$\mathrm{Na}$ tabela I, nota-se que de 573 problemas inventariados $145(25,3 \%)$ foram obtidos na entrevista, $218(38,1 \%)$ no exame físico, $23(4 \%)$ na evolução de entrada e $187(32,6 \%)$ na evolução diária.

Observa-se um maior número de problemas inventariados durante a entrevista e exame físico, $363(63,4 \%)$. Considerando que estas duas tapas de identificação de problemas fazem parte do histórico de enfermagem, constata-se que este instrumento é uma das principais fontes de detecção de problemas.

Deve-se, também, considerar que apesar do histórico de enfermagem ser realizado nas primeiras 48 horas de internação do paciente, a sua finalidade é justamente a de proporcionar o conhecimento do paciente e a identificação da totalidade dos problemas apresentados nesta ocasião. Por outro lado, na evolução diária, que é realizada durante todo o período de internação do paciente, apenas os novos problemas foram registrados, tendo portanto sido inventariados um total de $187(32,6 \%)$.

Esses resultados sugerem que o enfermeiro dispõe desde a admissão do paciente de dados que possa levá-lo a um planejamento bastante amplo da assistência de enfermagem a ser prestada a seus pacientes, complementando-os, posteriormente, com os achados dos dias que se sucedem à admissão.

Quanto à categorização, relacionada aos três níveis, $199(51,8 \%)$ os problemas inventariados nos exames físicos e $150(39,8 \%)$ na evolução diária foram categorizados como psicobiológicos. Esse resultado é compatível devido à própria finalidade do exame físico como uma etapa em que se evidenciam os problemas biológicos. Constata-se, porém, que nas evoluções diárias, os enfermeiros continuam atribuindo maior ênfase para a detecção de problemas nesse nível.

Em relação à categoria psicossocial, $28(84,8 \%)$ dos problemas foram detectados na entrevista. Cumpre esclarecer que o instrumento utilizado para a entrevista é direcionado para o levantamento de problemas nesse nivel.

Quanto aos problemas categorizados como psicobiológicos e psicosso. ciais, $92(65,2 \%)$ foram levantados durante a entrevista e $21(14,9 \%)$ durante a evolução diária.

Dos problemas categorizados como psicobiológicos, psicossocial e psicoespiritual, $11(73,3 \%)$ foram levantados na evolução diária. Tal fato, talvez possa ser atribuído a alguns procedimentos durante o período de internação como: cirurgia, cateterismo cardíaco e outros considerados invasivos, em virtude do paciente estar exposto a um maior risco de vida ou sofrimento.

Não foram inventariados problemas psicoespirituais nas diversas fases da $S A E$, talvez porque o próprio instrumento utilizado para detecção de problemas na admissão do paciente, não esteja direcionado para esse nível. Entretanto, outro aspecto poderia ser questionado: estariam os enfermej- 
ros despertados e preparados para o levantamento $e$ atendimento das necessidades psicoespirituais desses pacientes?

Em relação a evolução de entrada, observa-se que essa etapa foi a que identificou menor número de problemas $23(4 \%)$ em todas as categorias. Tal resultado pode ser atribuído ao fato de que na realização do histórico de enfermagem, via de regra, todos os problemas foram detectados e parece que o enfermeiro fez apenas uma síntese priorizando os principais problemas que serão abordados na prescrição de enfermagem.

\section{TABELA \|I}

Distribuição dos problemas inventariados e dos problemas relacionados na folha de elenco de problemas de acordo com as fases da SAE. InCor, São Paulo, 1986.

Fases de levantamento de problemas

\begin{tabular}{lrrrr}
\hline Histórico & 362 & 100,0 & 157 & 43,3 \\
Evolução de entrada & 24 & 100,0 & - & - \\
Evolução diária & 187 & 100,0 & 21 & 11,2 \\
Outros* & - & - & 35 & - \\
$\quad$ TOTAL & 573 & 100,0 & 213 & 37,1 \\
\hline
\end{tabular}

* Outros: Problemas que não foram inventariados nas fases de identificação de problemas, mas que foram relacionados na respectiva folha de elenco.

Dos 362 problemas inventariados no histórico de enfermagem, 157 $(43,3 \%)$ foram relacionados na folha de elenco de problemas, constituindo também a fase que fornece maior subsídio ao elenco de problemas. Talvez, isto se deva ao fato da própria facilidade de operacionalização do instrumento, visto que a etapa seguinte ao preenchimento do histórico de enfermagem, é a transcrição dos problemas para a folha de elenco.

Quanto à evolução diária, dos 187 problemas inventariados apenas 21 $(11,2 \%)$ foram relacionados na folha de elenco de problemas. Este dado é bastante significativo pois apesar dessa folha estar no mesmo Kardex que a prescrição de enfermagem diária, a mesma parece não estar sendo atualizada.

Durante a análise dos problemas elencados, constatou-se que 35 problemas foram relacionados na folha de elenco de problemas, mas não foram registrados em nenhuma das fases de identificação de problemas. Talvez, isto seja decorrente, de que estes problemas são elencados e abordados somente na prescrição de enfermagem. 
Observa-se, também, que os problemas relacionados na folha de elenco de problemas foram os que exigiram do enfermeiro uma atenção à longo prazo e parecem que não foram, na maioria das vezes, abordados na prescrição de enfermagem, como por exemplo: toma várias medicações por dia, dorme sob efeito de tranqüilizantes, extraiu a maioria dos dentes, ansioso quanto a sua hospitalização, entre outros.

Considerando-se que a folha de elenco de problemas foi proposta com a finalidade de se facilitar a visualização de toda a problemática apresentada pelo paciente, durante a sua hospitalização, parece que tal finalidade não está sendo alcançada devido a não atualização desse impresso.

\section{TABELA III}

Distribuição dos problemas inventariados e dos problemas relacionados na folha de elenco de problemas, de acordo com as suas categorias. InCor, São Paulo, 1986.

Categorias

Problema inventariado

$\mathbf{N}$

$\%$

100,0

167

43,4

Psicobiológico

384

33

141

Psicossocial

Psicobiológico,

Psicossocial e

Psicoespiritual

Psicoespiritual

TOTAL
100,0

31

93,9

100,0

14

9,9
Problema elencado

N

$\%$
Psicobiológico e

100,0

1

6,6

Do total de 384 problemas inventariados na categoria psicobiológica, $167(43,4 \%)$ foram elencados. Os problemas elencados, nesta categoria foram na sua maioria, os problemas identificados através do histórico de enfermagem; os problemas inventariados na evolução diária foram pouco elencados, o que sugere mais uma vez que a atualização da folha de elenco de problemas não está sendo adequada, apesar da facilidade de operacionalização já comentada anteriormente.

Acredita-se que a atualização da folha de elenco de problemas parece estar relegada a um segundo plano, pelo fato do enfermeiro não priorizá-la em função da própria sobrecarga de trabalho ou mesmo da praticidade e ela atribuída. 
Deve-se, também, considerar, que o enfermeiro assistencial não realiza apenas atividades relativas a sistematização da assistência, visto que cabe a ele, a execução de determinados procedimentos isolados (curativos, verificação de pressão arterial e orientação de exames, admissão e histórico de enfermagem, atendimento de intercorrências, orientações para alta hospitalar) e algumas atividades administrativas como coordenação da equipe de enfermagem, manutenção da ordem da unidade, atendimento às solicitações médicas e de outros membros da equipe multiprofissional, dentre outras.

Dos 33 problemas inventariados na categoria psicobiológica e psicossocial, $31(93,9 \%)$ foram elencados. Este dado é bastante significativo, pois a grande maioria desses problemas são identificados no histórico de enfermagem e, em seguida, elencados na folha de elenco de problemas.

Quanto aos problemas inventariados na categoria psicossocial, dos 141 , somente $14(9,9 \%)$ foram elencados. Parece que os problemas dessa área foram pouco valorizados sendo priorizados os da categoria psicobiológica; outra justificativa para esse fato, seria a dificuldade que o enfermeiro encontra em trabalhar com esses problemas e por esta razão, talvez não os elenca.

Tal situação sugere, ainda, uma indagação: estaria o paciente sendo visto pelos enfermeiros como um ser global, apresentando problemas não só da esfera biológica como, também, da psicossocioespiritual conforme a filosofia de enfermagem adotada pela instituição?

De 15 problemas inventariados na categoria psicobiológica, psicossocial e psicoespirtual, apenas $1(6,6 \%)$ foi elencado na folha de elenco de problemas. Isto parece ser justificado devido ao fato do enfermeiro não atualizar a folha de elenco de problemas, durante o período de internação do paciente pois a maioria destes problemas foram relacionados na evolução diária e são referentes a alguns procedimentos como cirurgia, cateterismo ou outros exames invasivos.

Através dos dados apresentados na Tabela 4, pode-se constatar que num total de 213 problemas elencados, $119(55,9 \%)$ foram abordados e $94(44,1 \%)$ não foram nas prescrições de enfermagem.

De 167 problemas elencados na categoria psicobiológica, 110 (65,8\%) foram abordados e $57(34,2 \%)$ não foram. Verifica-se através desses dados, que os problemas psicobiológicos foram abordados numa freqüência maior. Isto mostra que o enfermeiro encontra uma maior facilidade em trabalhar com problemas da esfera física.

Verifica-se que dos 31 problemas elencados na categoria psicobiológica e psicossocial $23(74,2 \%)$ não foram abordados na prescrição de enfermagem e $8(25,8 \%)$ foram abordados. Da mesma forma, dos 14 problemas da área psicossocial, $13(92,9 \%)$ não foram abordados e $1(71,7 \%)$ foi abordado. Na categoria psicobiológica, psicossocial e psicoespiritual, apenas um problema foi elencado, e o mesmo não foi abordado na prescrição de enfermagem. 
Relação entre problemas elencados, abordados e não abordados na prescrição de enfermagem, segundo sua categorização. InCor, São Paulo, 1986.

\begin{tabular}{|c|c|c|c|c|c|c|}
\hline \multirow{3}{*}{ Categorias } & \multicolumn{6}{|c|}{ PROBLEMA ELENCADO } \\
\hline & \multicolumn{2}{|c|}{ Abordado } & \multicolumn{2}{|c|}{ Não abordado } & \multicolumn{2}{|c|}{ TOTAL } \\
\hline & $\mathbf{N}$ & $\%$ & $\mathbf{N}$ & $\%$ & $\mathbf{N}$ & $\%$ \\
\hline Psicobiológica & 110 & 65,8 & 57 & 34,2 & 167 & 100,0 \\
\hline $\begin{array}{l}\text { Psicobiológica } \\
\text { e Psicossocial }\end{array}$ & 8 & 25,8 & 23 & 74,2 & 31 & 100,0 \\
\hline Psicossocial & 1 & 7,1 & 13 & 92,9 & 14 & 100,0 \\
\hline $\begin{array}{l}\text { Psicobiológica } \\
\text { Psicossocial e } \\
\text { Psicoespiritual }\end{array}$ & 一 & - & 1 & 100,0 & 1 & 100,0 \\
\hline Psicoespiritual & - & - & - & - & - & - \\
\hline TOTAL & 119 & 55,9 & 94 & 44,1 & 213 & 100.0 \\
\hline
\end{tabular}

Estes dados refletem uma tendência do enfermeiro para o não atendimento das necessidades psicossocioespirituais afetadas. Desta forma, algumas suposições podem ser levantadas:

1. Estaria o enfermeiro apresentando dificuldades para trabalhar com problemas desta categoria?

2. Estaria o enfermeiro despertado para a importância destes problemas dentro do contexto global da problemática assistencial?

3. Estaria o enfermeiro valorizando tais problemas, propondo ações adequadas ao seu atendimento e no entanto, negligenciando o seu registro?

OLIVEIRA ${ }^{17}$ considera que parece faltar aos enfermeiros conhecimento adequado para identificação de problemas psicossociais, bem como habilidade para propor ações adequadas relacionadas ao mesmo", e reforça que "o fato da área psicobiológica apresentar um número mais elevado de problemas em relação à psicossocial possa ser explicado pela existência de poucos estudos em nosso meio sobre as necessidades psicossociais e pelo enfoque predominantemente técnico e voltadas às necessidades psicobiológicas dada ao ensino em nossas Escolas de Enfermagem".

PAIM ${ }^{19}$ relata que continua ocorrendo com certa freqüência "uma certa omissão quanto às responsabilidades diagnósticas do enfermeiro com relação às necessidades psicossociais, e psicoespirituais do paciente".

Os resultados obtidos, na Tabela 4, parecem confirmar as posições das autoras referenciadas.

A Tabela 5 mostra em freqüência absoluta as categorias dos problemas abordados na prescrição de enfermagem. Do total de 245 problemas abordados na prescrição de enfermagem, 205 são problemas psicobiológicos, 
12 psicobiológicos e psicossociais, 3 psicossociais e 25 psicobiológicos, psicossociais e psicoespirituais. Não foram abordados problemas psicoespirituais.

\section{TABELA V}

Categorização dos problemas abordados na prescrição de enfermagem. InCor, São Paulo, 1986.

Categorias

PROBLEMA ABORDADO NA

Categorias

Psicobiológica PRESCRIÇĀO DE ENFERMAGEM

Psicobiológica e

Psicossocial 12

Psicossocial 205

Psicobiológica,

Psicossocial e

Psicoespiritual

Psicoespiritual

TOTAL

Esses resultados reforçam os resultados anteriores, ou seja, o enfermeiro trabalha predominantemente com problemas da área psicobiológica.

Verifica-se na tabela VI, que foram inventariados um total de 573 problemas sendo 245 abordados na prescrição de enfermagem.

Dos 384 problemas elencados na categoria psicobiológica, apenas 205 foram abordados. Comprova-se, mais uma vez, que a maioria dos problemas abordados são da categoria psicobiológica.

\section{TABELA VI}

Distribuição dos problemas inventariados e dos problemas abordados na prescrição de enfermagem, de acordo com suas categorias.

InCor, São Paulo, 1986.

\begin{tabular}{|c|c|c|}
\hline Categorias & $\begin{array}{c}\text { Inventariado } \\
\mathbf{N}\end{array}$ & $\begin{array}{c}\text { PROBLEMA } \\
\text { Abordado na prescrição de enfermagem } \\
\mathbf{N}\end{array}$ \\
\hline Psicobiológica & 384 & 205 \\
\hline $\begin{array}{l}\text { Psicobiológica e } \\
\text { Psicossocial }\end{array}$ & 141 & 12 \\
\hline Psicossocial & 33 & 3 \\
\hline $\begin{array}{l}\text { Psicobiológica, } \\
\text { Psicossocial e } \\
\text { Psicoespiritual }\end{array}$ & 15 & 25 \\
\hline Psicoespiritual & - & - \\
\hline TOTAL & 573 & 245 \\
\hline
\end{tabular}


$\mathrm{Na}$ categoria psocobiológica e psicossocial, foram inventariados 141 problemas, dos quais apenas 12 foram abordados na prescrição de enfermagem. Da mesma forma foram inventariados 33 problemas na categoria psicossocial, sendo apenas 3 abordados na prescrição de enfermagem.

No geral, verifica-se que nas diferentes categorias foram inventariados maior número de problemas do que abordados. Isto pode implicar que a própria definição de problema de enfermagem adotado pela instituição, pode não estar clara para a maioria dos enfermeiros ou que, como já foi discutido anteriormente, problemas menos específicos e que exijam uma atenção a longo prazo, não sejam considerados talvez como problema de enfermagem.

E interessante notar entretanto, que foram abordados 25 problemas da categoria psicobiológica, psicossocial e psicoespiritual na prescrição de enfermagem, apesar de somente 15 problemas desta área terem sido inventariados. A primeira vista este dado parece incoerente, e na tentativa de explicar tal fato observou-se que alguns problemas abordados na prescrição de enfermagem não estavam registrados nas fases de levantamento de problemas, a saber: histórico de enfermagem, evolução de entrada e evolução diária, o que mostra que estes problemas se limitaram apenas à prescrição de enfermagem.

Isto sugere que possa ter ocorrido falhas no registro destes problemas, pois conforme preconiza a instituição, todos os problemas abordados na prescrição de enfermagem deverão estar registrados na evolução de enfermagem quer seja para justificar a sua abordagem, ou para caracterizar a evolução do problema.

\section{TABELA VII}

Relação entre problemas inventariados, abordados e não abordados na prescrição de enfermagem, de acordo com as fases da SAE. InCor, São Paulo, 1986.

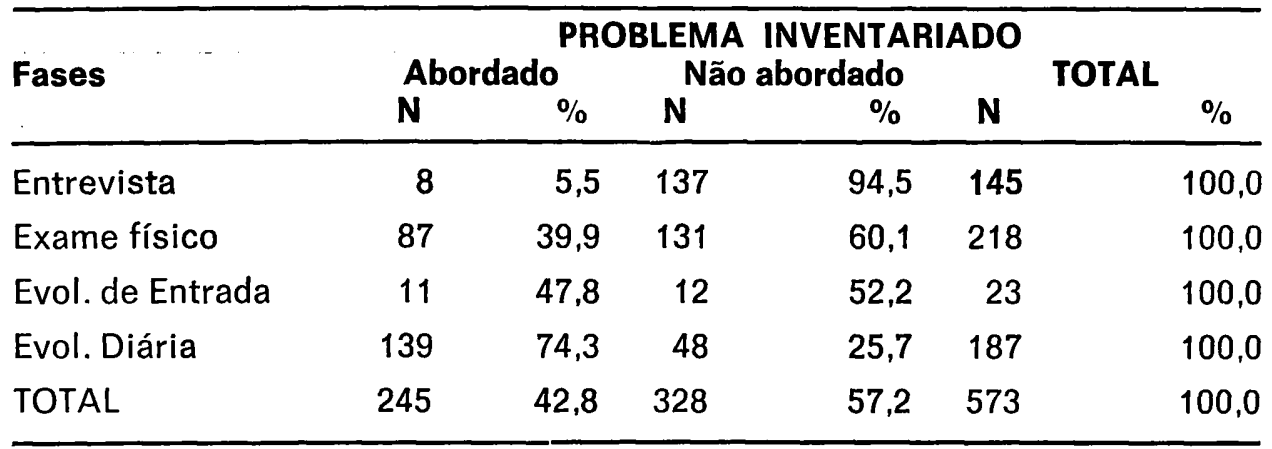

Verifica-se por meio da Tabela 7 que, dos 573 problemas inventariados, $245(42,8 \%)$ foram abordados e $328(57,2 \%)$ não foram aborados na prescrição de enfermagem. 
Dos 145 problemas inventariados durante a entrevista, apenas $8(5,5 \%)$ foram abordados na prescrição de enfermagem e de 218 problemas inventariados no exame físico, $87(39,9 \%)$ problemas foram abordados. (Figura 7).

Tais dados sugerem que os problemas identificados no histórico de enfermagem são poucos abordados na prescrição de enfermagem. OLIVEIRA ${ }^{19}$ considera que o "histórico de enfermagem é a etapa mais importante que identifica o maior número de problemas de enfermagem que 0 paciente apresenta durante a hospitalização, porém é a fase em que um menor número de problemas são abordados".

Da evolução de entrada foram abordados na prescrição $11(47,8 \%)$ problemas, e da evolução diária $139(74,3 \%)$ foram abordados na prescrição de enfermagem. Por meio desses dados observa-se que os enfermeiros tendem a procurar soluções para os problemas imediatos, constatados no dia-a-dia, reportando-se um menor número de vezes ao histórico de enfermagem ou a folha de elenco de problemas.

Algumas indagações a esse respeito podem ser feitas:

1. Qual seria o significado atribuído pelos enfermeiros ao histórico de enfermagem?

2. Estaria o mesmo sendo preenchido somente no sentido de atender a uma exigência da instituição?

3. Disporiam os enfermeiros de tempo real para revisar o histórico de enfermagem e a folha de elenco de problemas, diariamente ao proceder a evolução e a prescrição de enfermagem?

\section{TABELA VIII}

Relação entre problemas inventariados, abordados e não abordados na prescrição de enfermagem, de acordo com suas categorias. InCor. São Paulo, 1986.

\begin{tabular}{|c|c|c|c|c|c|c|}
\hline \multirow{3}{*}{ Categorias } & \multicolumn{6}{|c|}{ PROBLEMA INVENTARIADO } \\
\hline & \multicolumn{2}{|c|}{ Abordado } & \multicolumn{2}{|c|}{ Não abordado } & \multicolumn{2}{|c|}{ TOTAL } \\
\hline & $\mathbf{N}$ & $\%$ & $\mathbf{N}$ & $\%$ & $\mathbf{N}$ & $\%$ \\
\hline Psicobiológica & 208 & 54,3 & 175 & 45,7 & 383 & 100,0 \\
\hline $\begin{array}{l}\text { Psicobiológica e } \\
\text { Psicossocial }\end{array}$ & 23 & 16,1 & 120 & 83,9 & 143 & 100,0 \\
\hline Psicossocial & 2 & 6,5 & 29 & 93,5 & 31 & 100,0 \\
\hline $\begin{array}{l}\text { Psicobiológica, } \\
\text { Psicossocial e } \\
\text { Psicoespiritual }\end{array}$ & 12 & 75,0 & 4 & 25,0 & 16 & 100,0 \\
\hline Psicoespiritual & - & 一 & - & - & - & - \\
\hline TOTAL & 245 & 42,8 & 328 & 57,2 & 573 & 100,0 \\
\hline
\end{tabular}


$\mathrm{Na}$ Tabela 8 , observa-se que dos 383 problemas inventariados na categoria psicobiológica, $208(54,3 \%)$ foram abordados. Novamente, constata-se que o enfermeiro tem maior facilidade para abordar problemas dessa natureza.

Dos 143 problemas inventariados na categoria psicobiológica e psicossocial, $23(16,1 \%)$ foram abordados na prescrição de enfermagem e 20 $(83,9 \%)$ não foram. Dos 31 problemas inventariados na categoria psicossocial, apenas $2(6,5 \%)$ foram abordados.

Constata-se outra vez a dificuldade que o enfermeiro encontra em prescrever ações para atender esses problemas, conforme discutido anteriormente.

Quanto aos 16 problemas da categoria psicobiológica, psicossocial e psicoespiritual, $12(75 \%)$ foram abordados. Isto talvez seja justificável pelo fato de terem sido categorizados nesse nivel, os procedimentos invasivos que envolvem algum risco de vida ou sofrimento.

\section{TABELA IX}

Distribuição dos problemas inventariados, elencados e abordados na prescrição de enfermagem, segundo suas categorias.

InCor. São Paulo, 1986.

\section{PROBLEMAS}

\begin{tabular}{|c|c|c|c|c|c|c|}
\hline \multirow[t]{2}{*}{ Categorias } & \multicolumn{2}{|c|}{ Inventariado } & \multicolumn{2}{|c|}{ Elencado } & \multicolumn{2}{|c|}{$\begin{array}{c}\text { Abordado na } \\
\text { prescrição } \\
\text { de enfermagem }\end{array}$} \\
\hline & $\mathbf{N}$ & $\%$ & $\mathbf{N}$ & $\%$ & & $\%$ \\
\hline Psicobiológica & 384 & 67,0 & 167 & 78,4 & 205 & 83,7 \\
\hline $\begin{array}{l}\text { Psicobiológica } \\
\text { Psicossocial }\end{array}$ & 141 & 24,6 & 31 & 14,5 & 12 & 4,9 \\
\hline Psicossocial & 33 & 5,8 & 14 & 6,6 & 3 & 1,2 \\
\hline $\begin{array}{l}\text { Psicobiológica, } \\
\text { Psicossocial e } \\
\text { Psicoespiritual }\end{array}$ & 15 & 2,6 & 1 & 0,5 & 25 & 10,2 \\
\hline Psicoespiritual & - & - & - & - & - & - \\
\hline TOTAL & 573 & 100,0 & 213 & 100,0 & 245 & 100,0 \\
\hline
\end{tabular}

O objetivo desta tabela, foi mostrar a distribuição dos dados coletados durante este estudo, de forma a visualizar, comparativamente, os diferentes momentos em que estes problemas foram identificados conforme as suas categorias.

Do total de 573 problemas inventariados, $384(67,0 \%)$ forma categorizados como psicobiológicos. Dos 213 problemas elencados, $167(78 \%)$ 
estão contidos nesta mesma categoria. Em relação, aos problemas abordados na prescrição de enfermagem, dos 245 problemas, $205(83,7 \%)$ também foram categorizados como psicobiológica.

Quanto a categoria psicobiológica e psicossocial, foram inventariados $141(24,6 \%)$, elencados $31(14,5 \%)$ e $12(4,9 \%)$ abordados na prescrição de enfermagem.

Considerando-se a categoria psicossocial, foram inventariados 33 $(5,8 \%)$ elencados $14(6,6 \%)$ e abordados na prescrição de enfermagem, $3(1,2 \%)$.

Da mesma forma, foram encontrados os seguintes resultados para a categoria psicobiológica, psicossocial e psicoespiritual: inventariados 15 $(2,6 \%)$, elencados $1(0,5 \%)$ e abordados na prescrição de enfermagem $25(10,2 \%)$.

Os problemas da categoria psicoespiritual não foram inventariados, elencados e nem abordados na prescrição de enfermagem.

Observa-se nesta tabela que dos 573 problemas inventariados somente $245(42,8 \%)$ foram abordados nas prescrições de enfermagem. Frente a esses dados pergunta-se:

1. O que teria ocorrido com os $328(57,2 \%)$ problemas apresentados pelos pacientes e para os quais não foram propostas ações de enfermagem?

2. Que valor seria atribuído ao conhecimento dos problemas de enfermagem apresentados pelo paciente, se posteriormente não houverem propostas de ações para o mesmo?

Tais resultados levariam a uma proposta, no sentido de que fossem analisados os recursos humanos disponíveis na instituição para efetivar o planejamento de assistência de enfermagem a ser prestada aos pacientes, e talvez, frente a esta realidade, se reestudar a relação numérica enfermeiro/paciente, a serem envolvidos e prescritos, de forma que, o paciente fosse realmente atendido na totalidade dos problemas apresentados e detectados pelo enfermeiro.

\section{CONCLUSÃO}

Foram inventariados 573 problemas, elencados 213 e abordados 245 . - Dos 573 problemas inventariados:

- Quanto a fase de identificação de problemas:

$218(38,1 \%)$ problemas foram inventariados no exame físico, 187 $(32,6 \%)$ na evolução diária, $145(25,3 \%)$ na entrevista e $23(4 \%)$ na evolução de entrada.

- Quanto a categorização e fase de identificação de problemas: 384 problemas pertenciam a categoria psicobiológica; destes 199 
$(51,8 \%)$ foram inventariados no exame físico, 150 (39\%) na evolução diária, $24(6,3 \%)$ na entrevista e $11(2,9 \%)$ na evolução de entrada.

- 141 problemas pertenceram à categoria psicobiológica e psicossocial, destes $92(65,2 \%)$ foram inventariados na entrevista, $21(14,9 \%)$ na evolução diária $19(13,5 \%)$ no exame físico e $9(6,4 \%)$ na evolução de entrada.

33 problemas pertenceram à categoria psocossocial, destes 28 $(84,8 \%)$ foram inventariados na entrevista e $5(15,2 \%)$ na evolução diária.

15 problemas pertenceram à categoria psicobiológica, psicossocial e psicoespiritual, destes $11(73,3 \%)$ foram inventariados na evolução diária, $3(20 \%)$ na evolução de entrada e $1(6,7 \%)$ na entrevista.

- Não foram inventariados problemas na categoria psicoespiritual.

- Quanto a abordagem e fase de identificação de problema:

$245(42,8 \%)$ problemas foram abordados na prescrição de enfermagem e $328(57,2 \%)$ não foram. Do total de problemas inventariados e abordados, 139 foram levantados na evolução diária, 87 no exame físico, 11 na evolução de entrada e 8 na entrevista.

- Quanto a abordagem e categorização:

Do total de problemas abordados, 208 pertencem a categoria psicobiológica, 23 a categoria psicobiológica e psicossocial, 12 à categoria psicobiológica, psicossocial e psicoespiritual e 2 à categoria psicossocial.

- De 213 problemas relacionados na folha de elenco de problemas:

- Quanto a fase de identificação do problema:

Foram elencados 157 problemas do histórico de enfermagem, 21 da evolução diária nenhum da evolução de entrada e 35 problemas que não foram inventariados nas fases de identificação de problemas da SAE, mas que estavam relacionados na folha de elenco de problemas.

- Quanto a abordagem e categorização:

$119(55,8 \%)$ problemas foram abordados na prescrição de enfermagem e $94(44,1 \%)$ não foram, dos problemas abordados 110 pertencem à categoria psicobiológica, 8 à categoria psicobiológica e psicossocial e 1 à categoria psicossocial.

- De 245 problemas abordados na prescrição de enfermagem:

- Quanto a categorziação:

205 problemas pertenciam à categoria psicobiológica, 12 à categoria psicobiológica e piscossocial, 25 à categoria psicobiológica, psicossocial e psicoespiritual e 3 à categoria psicossocial. 


\section{CONSIDERAÇÕES FINAIS}

Os resultados encontrados no estudo realizado possibilitaram algumas reflexões sobre a sistemática da assistência de enfermagem.

Acredita-se que o planejamento seja fator fundamental para garantir uma assistência de qualidade. Entretanto, sabe-se, que qualquer proposta de ação necessita periodicamente de uma avaliação criteriosa para que se tenha noção do que de fato está sendo efetivado no dia-a-dia.

Para que a metodologia adotada seja adequada e aprimorada no sentido de torná-la cada vez mais efetiva, alguns aspectos devem ser considerados. Um deles é a relação numérica enfermeiro/paciente, pois verifica-se que quando o enfermeiro tem atribuição de evoluir e prescrever um grande número de pacientes, e em função do tempo disponível para tal, passa a fazê-lo de maneira menos profunda para conseguir realizar suas tarefas. Tal situação, faz com que além dos pacientes não serem atendidos nas suas reais necessidades, o profissional sinta-se insatisfeito por ter plena consciência de não estar desenvolvendo suas atividades como desejaria.

Um outro aspecto diz respeito às funções desempenhadas pelo enfermeiro, pois na prática diária observa-se que muitas delas poderiam ser perfeitamente executadas por outro membro da equipe de enfermagem que tivesse recebido treinamento adequado para tal, dispondo assim o enfermeiro de maior tempo para os aspectos mais diretamente relacionados ao planejamento, implementação e avaliação da assistência de enfermagem prestada aos seus pacientes.

Outro fator relevante é o conceito de enfermagem e de assistência de enfermagem adotados e professados pela instituição.

Sabe-se que os enfermeiros ao chegarem numa instituição, por terem recebido uma formação profissional heterogênea trazem consigo concepções diferentes sobre a amplitude que a asistência de enfermagem possa assumir, cabendo portanto a instituição adotar e difundir, entre os seus profissionais, a filosofia sobre o qual estará embasada a sua assistência, favorecendo com isso, a uniformidade das condutas adotadas pelos profissionais nas diferentes situações.

Quando se adota o conceito de assistência de enfermagem determinase o alcance da mesma no que diz respeito ao atendimento do homem na sua totalidade, e uma vez, assumida a responsabilidade do atendimento global ao ser humano, caberá à instituição, avaliar a competência de seus profissionais para o alcance da sua proposta e, complementando os conhecimentos necessários, visando capacitá-lo, para a detecção e atendimento dos problemas decorrentes das alterações das necessidades biopsicossócioespirituais.

A avaliação e reciclagem dentro do contexto de manutenção de uma proposta de trabalho são etapas imprescindiveis, pois nelas, os profissionais têm oportunidade não só de análise e reflexão sobre sua prática efetiva como, também, da ampliação dos conhecimentos que se fazem 
necessários. Ambas são fundamentais, para que os ajustes necessários, que garantem a homogeneidade de crença e ações por parte dos enfermeiros sejam preservadas.

Para tanto, acredita-se que seja necessário a adoção de um esquema de pausas periódicas, que promovam aos enfermeiros a oportunidade de discutirem e analisarem os problemas encontrados na operacionalização da SAE, em suas atividades diárias para que a partir daí, sejam efetivadas as mudanças necessárias, que assegurem a continuidade e aprimoramento da proposta inicial.

ZANEI, S.S.V.; OLIVEIRA, M.E.D. de; ERNESTO, D.Z.L. Nursing problems and its relationship to the nursing prescription: an retrosprectiv study. Rev. ESC. Ent. USP, São Paulo, Paulo, 22 (n.. especial): 119-147, June, 1988.

The opportunity for this study took place at INCOR - Instituto do Coração do Hospital das Clínicas da Faculdade de Medicina da Universidade de São Paulo, where nursing care method is conducted towards its individualization and qualification. During daily training at the Hospital units, it was felt some inadequation between the theoretical nursing care pattern and its practical implementation.

In an attempt to demonstrate the real status of nursing care this study is focused on the relationship between the patient's problems identification and the nursing care prescriptions, classifying those problems in psychobiological, psychosocial and psychospiritual. The compilation of data indicates the necessity of re-evaluation of the presently used methodology. Aditional commensts are made related to the specific theme of this study.

UNITERMS: Nursing care. Nursing prescriptions. Patient care planning.

\section{REFERENCIAS BIBLIOGRAFICAS}

1. ANGERAMI, E.L.S. et alii. Análise crítica das anotações de enfermagem. Rev. Bras. Enf. Brasília, 29(4):28-37, out./dez. 1976.

2. ARAUJO, M.V. et alii. Auditoria em enfermagem. Rev. Bras. Enf., Brasília, 31(4): 466-77, out./dez. 1978.

3. BARBATO, M.G. et alii. Problemas psicossocio-espirituais dos coronariopatas internados em unidade coronariana. Rev. Bras. Enf., Brasília, 35(1):7-16, jan./mar. 1982.

4. BERGMAN, R.N. Evaluation of nursing care - could it make a difference Int. J. Nurs. Stud., Oxford, 19(2):53-60, mar. 1982.

5. CERQUEIRA, L.T. Auditoria em enfermagem: contribuição para o desenvolvimento de um instrumento de mensuração da qualidade dos cuidados de enfermagem a pacientes hospitalizados. Rio de Janeiro, 1977. (Tese de Livre Docência - Escola de Enfermagem Ana Neri - U.R.F.J.)

6. CLARK, J. When should nurses prescribe? Occup. Health, London 30(2):60-3, Feb. 1978.

7. COSTA, S.C. Mensuração da qualidade dos cuidados de enfermagem: apresentação de um método para auditoria de plano de cuidados. Rio de Janeiro, 1982. (Dissertação de Mestrado - Escola de Enfermagem Ana Neri da U.F.R.J.J. 
8. DANIEL, L.F. A enfermagem planejada. 3. ed. São Paulo, EPU, 1981. 136 p.

9. FERNANDES, R.A.Q. Processo de enfermagem e suas implicações na resolução de problemas físicos de pacientes hospitalizados. São Paulo, 1980. (Dissertação de Mestrado - Escola de Enfermagem da USP).

10. GutierReZ, M.G.R. de \& GONÇALVES, L.H.T. Aplicação do Processo de Enfermagem: tempo necessário. Enf. Novas Dimens., São Paulo, 5(2):23-26, mar./abr. 1979.

11. HORTA, W.A. Processo de enfermagem. São Paulo, EPU/EDUSP, 1979. 98 p.

12. KRON, T. Manual de enfermagem. Rio de Janeiro, Interamericana, 1978. 251 p.

13. KURCGANT, P. Auditoria em enfermagem. Rev. Bras. Enf., Brasília, 29(3):106-124, jul./set. 1976.

14. Plano de cuidados de enfermagem - necessidade administrativa. Enf. Novas Dimens., São Paulo, 2(3):139-141, jul./ago. 1976.

15. MOHANA, J. O mundo e eu. 2. ed. Rio de Janeiro, Agir, 1964. 231 p.

16. MOUGHTON, M. The patient: a partner in the health care process, Nurs Clin North Am., Philadelphia, 17(3):467-479, 1982.

17. OLIVEIRA, S.S.G. Auditoria de enfermagem: uma experiência em um hospital universitário. São Paulo, 1982. (Dissertação de Mestrado - Escola de Enfermagem da USP).

18. PAIM, L. Problemas, prescrições e planos: um estilo de assistência de enfermagem. Brasilia, ABEn, 1978. $52 \mathrm{p}$.

19. Algumas considerações de enfermagem sobre as necessidades psIcossociais e psicoespirituais dos pacientes. Rev. Bras. Enf., Brasília, 32(2):160-166, abr./jun. 1979.

20. PAIM, R.C.N. Metodologia científica em enfermagem. Rio de Janeiro, Ed. Espaço e Tempo, 1986. $211 \mathrm{p}$.

21. ROLIM, E.J. Aplicação da metodologia de efermagem no cuidado de um paciente. Rev. Esc. Enf. USP, São Paulo, 4(1/2): 81-95, mar./set. 1970.

22. SOUZA, F.P. Importância da auditagem nas organizações hospitalares. Rev. Paul. Hosp., São Paulo, 17(8):49-50, ago. 1969. 


\section{ANEXO I}

\section{HOSPITAL DAS CLINICAS - FMUSP INSTITUTO DO CORAÇÃO DIVISÃO DE ENFERMAGEM}

Nome:

Idade:

Natr.:

Grau de Instr.:
Sexo:

RG:

Est. Civil:

Proced.:

Diagnóstico:

\section{HISTÓRICO DE ENFERMAGEM}

Quarto: ........... Leito:

Filhos:

Religião:

\section{AMBIENTE E HÁBITOS}

1.1 Moradia (unifamiliar ou coletiva, destino do lixo, fornecimento de água):

1.2 Sono e Repouso ((duração média, horária, hábitos relacionados):

1.3 Cuidado Corporal (banho, higiene oral, freqüência, horário):

1.4 Recreação e Lazer (atividades de lazer, práticas esportivas):

1.5 Alimentação (apetite, preferências, intolerâncias, ingestão hídrica):

1.6 Manutenção da Saúde (tabagismo, etilismo, outras doenças, alergias, medicações em uso, imunizações):

2. EXAME FISICO

2.1 Dados Gerais:

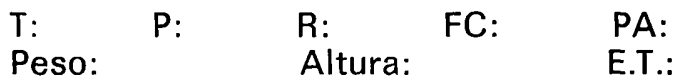

2.2 Neurológico (nível de consciência, reações, orientação, sensibilidade tátil, paralisias etc.):

2.3 Pele e Fâneros (cor, têmpera, edema, solução de continuidade, manchas, sujidades, higiene e coloração das unhas):

2.4 Músculo Esquelético (Motilidade, postura, condições dos $\mathrm{mm}$ para injeções, dores articulares ou musculares): 
ANEXO II

HOSPITAL DAS CLINICAS - FMUSP

INSTITUTO DO CORAÇÃO

DIVISÃO DE ENFERMAGEM

ELENCO DE PROBLEMAS

Nome:

Reg.:

Idade:

Sexo:

Unidade: Leito:

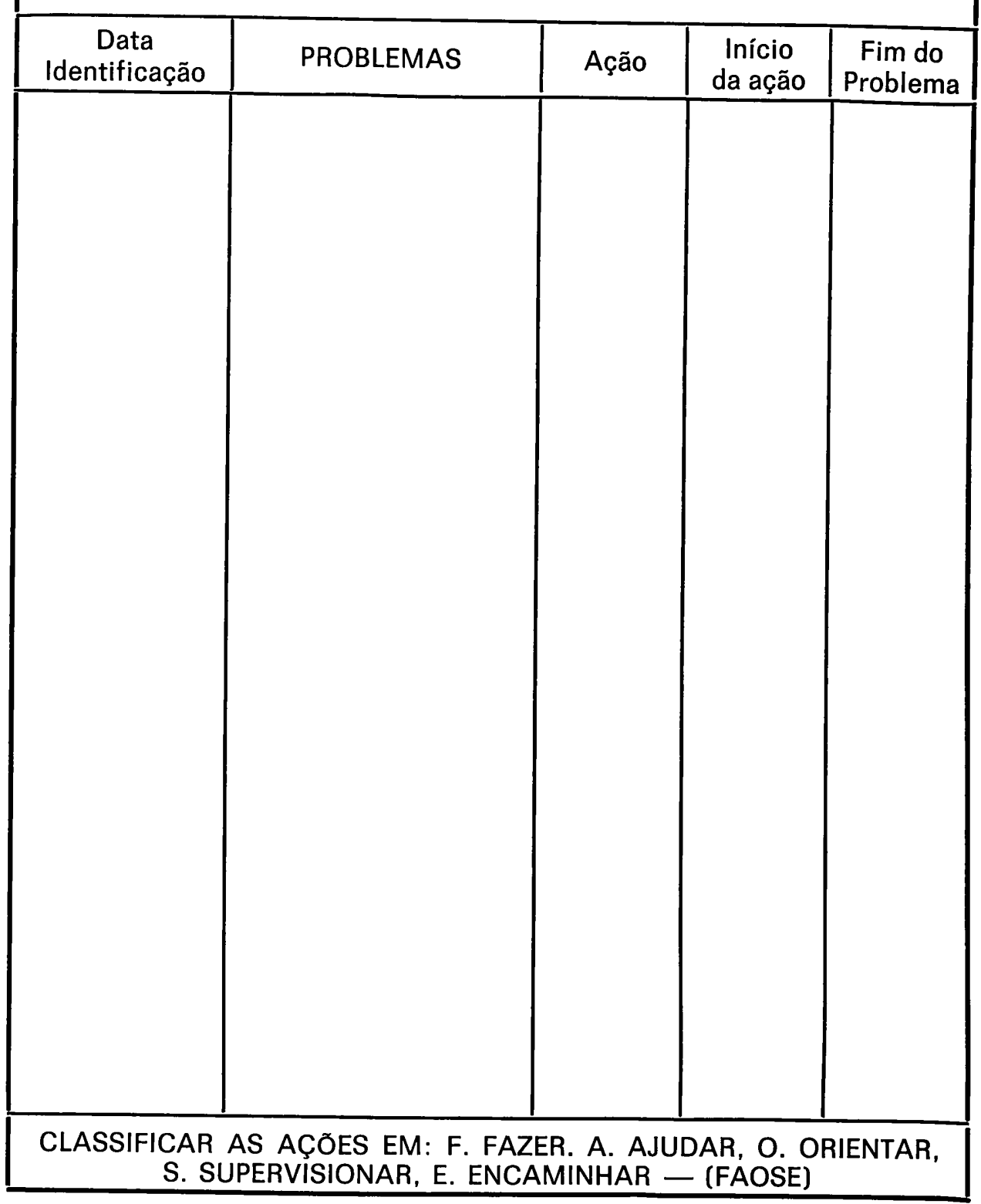

Rev. Esc. Enf. USP, Săo Paulo, 22 (n. especial): 119-147, ago. 1988. 


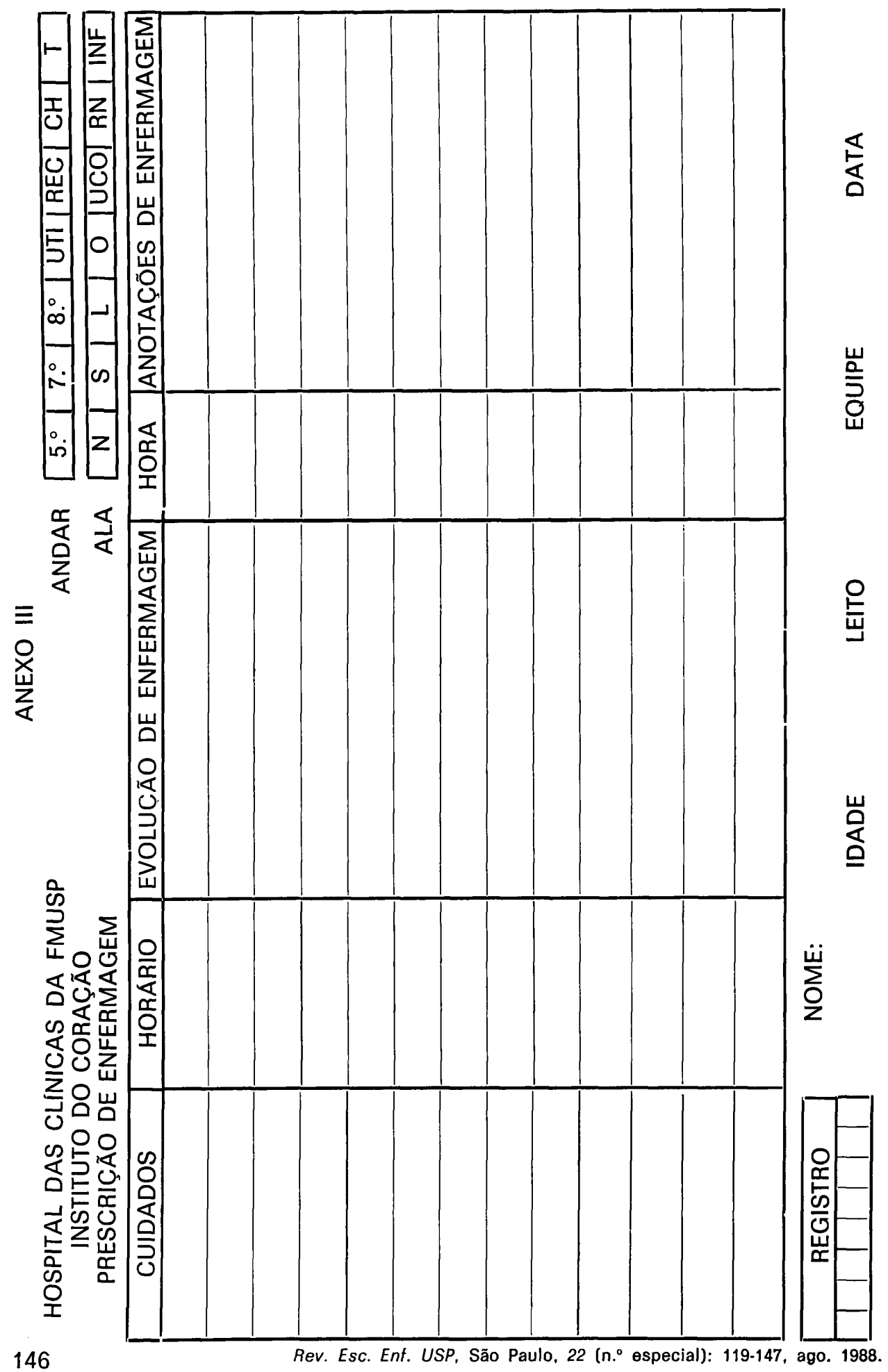


ANEXO IV

NOME:

$R G$ :

IDADE: SEXO:

DIAG.:
LEITO:
DATA INT.:
DATA CIRURG.:
ALTA:

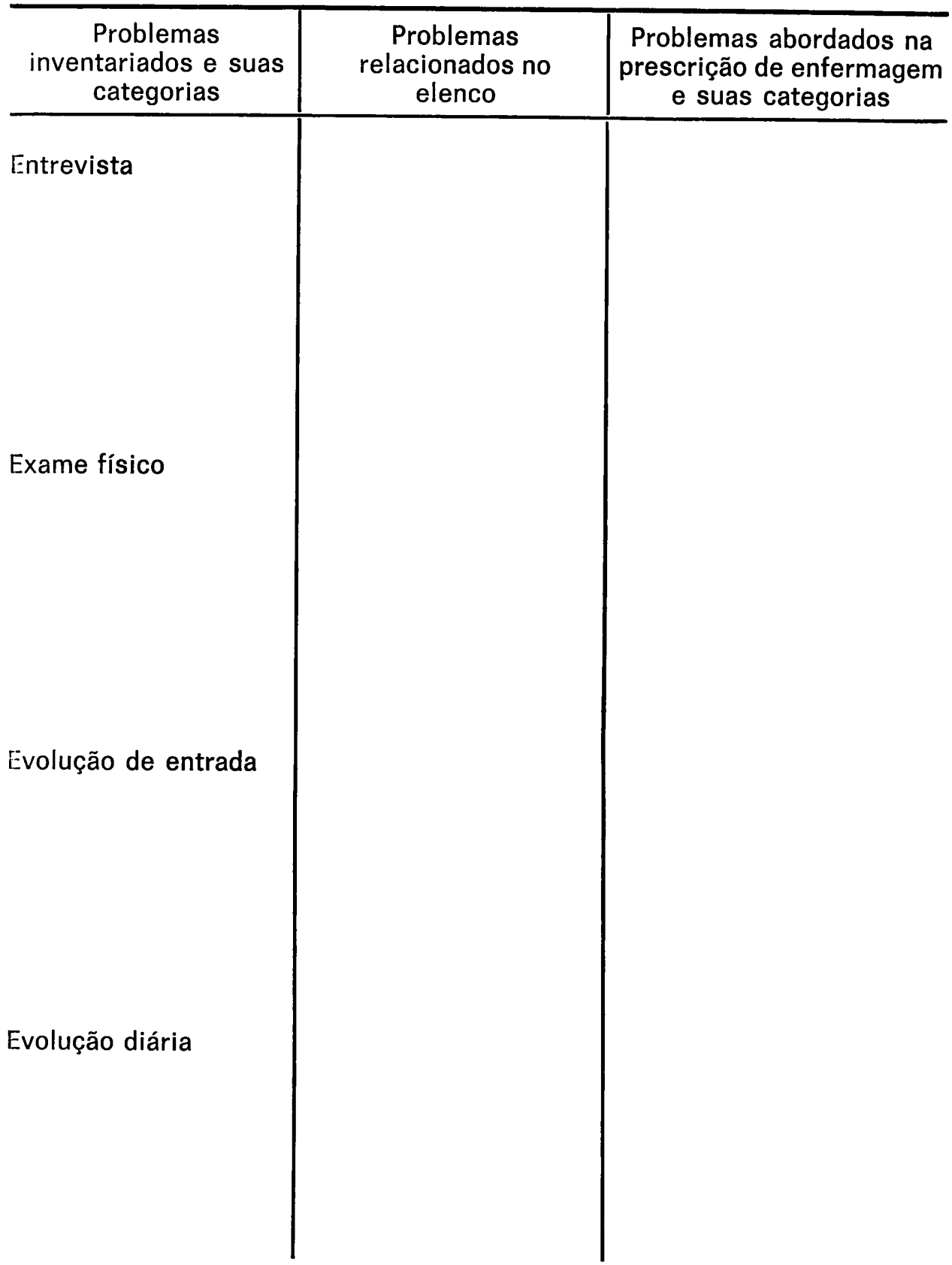

